\title{
Intraspecific Divergence Associated with a Biogeographic Barrier and Climatic Models Show Future Threats and Long-Term Decline of a Rainforest Conifer
}

\author{
Rohan Mellick, ${ }^{\mathrm{a}, \mathrm{b}, *}$, Maurizio Rossetto ${ }^{\mathrm{a}}$, Chris Allen ${ }^{\mathrm{a}}$, Peter D. Wilson ${ }^{\mathrm{d}}$, Robert S. Hill ${ }^{\mathrm{c}}$ and Andrew \\ Lowe ${ }^{\mathrm{b}}$
}

\author{
${ }^{a}$ National Herbarium of NSW, The Royal Botanic Gardens and Domain Trust, Sydney, NSW 2000, Australia \\ ${ }^{b}$ Australian Centre for Evolutionary Biology and Biodiversity, School of Earth and Environmental Sciences, University \\ of Adelaide, SA 5005, Australia
}

${ }^{c}$ Faculty of Sciences, University of Adelaide, SA 5005, Australia

${ }^{d}$ Department of Biological Sciences, Macquarie University, NSW 2019, Australia

\begin{abstract}
A capacity to foresee the shift in species' range and the demographic response to future climate change is integral to effective conservation planning. Here we model the future climate-driven range shift, and compare it with past range shift, along a latitudinal gradient in two population groups of a late-successional rainforest conifer (Podocarpus ela$t u s$ ), genetically differentiated over the Clarence River Corridor biogeographic barrier (Northern NSW, East Australian Rainforests). Climate envelope modelling of the past-current-future distributions of the two groups and a coalescent-based isolation-with-migration model investigated divergence times and effective population sizes among the current genetic disjunctions in the species. This suggests differential range shift (i.e. expansion in the north and contraction in the south) will continue in the future, with a southern range shift also occurring in both climatic models. The origin of the Clarence River Corridor dividing the two population groups was inferred by molecular analysis to be prior to the last glacial maximum (LGM). Another divergence in the south $(19 \mathrm{ka})$ is indicative of slow consistent habitat contractions since the LGM (21 ka). We recommend the southern and Macleay Overlap Zone (far-eastern Australia) populations as priority areas for protection based upon intraspecific diversity and past-current-future habitat suitability. The integrated approach shows that this widely distributed species is more at risk than expected from current climate change and other anthropogenic effects.
\end{abstract}

Keywords: Clarence River Corridor, Climate-induced range shift, Far-eastern Australia, Genetic diversity/structure, Localised extinction, Macleay Overlap Zone, Past-current-future, Population expansion/contraction, Rainforest.

\section{INTRODUCTION}

In view of projected climate change[1-3], understanding climate-induced range shifts is key to the conservation of populations [4], species [5,6] and communities[7-9]. For populations to survive they either need to adapt [10-12], migrate into suitable conditions along environmental gradients $[13,14]$ or a combination of both. Defining the abiotic limitations on a species distribution, using either physiological $[15,16]$ or occurrence data $[17,18]$, refines the understanding of current habitat suitability and the prediction of future range shifts. Although it has been shown that single species do respond independently during climate change, fossil records show that some species-community associations can persist through time $[19,20]$ where the overarching abiotic limitations on the community affect the association and

*Address correspondence to this author at the National Herbarium of NSW, The Royal Botanic Gardens and Domain Trust, Sydney, NSW 2000, Australia; Tel: +61 29231 8147; Fax: +61 29251 7231;

E-mail: rohan.mellick@rbgsyd.nsw.gov.au co-occurrence of species. We can refine the prediction of future community level dynamics for the purposes of conservation and management by considering the climate-driven changes in a long-lived species, closely associated in the fossil record with a specific community type.

\subsection{The Shift of Climatic Suitability and Localised Ex- tinction}

Localised extinction risk varies due to species traits and spatial characters of the physical environment owing to the combined and interactive effects of ecology and geography $[21,22]$. Rapid climate change increases the likelihood of localised extinction by shifting the "climatic envelope" of a population outside of the current geographic range [4]. Survival is dependent on the species' traits, potential to adapt (natural selection), genomic plasticity (response to environmental changes) and/or the rate at which a species can shift its range in response. Northern hemisphere palynological studies have revealed rapid migration rates $(100-1000 \mathrm{~m} / \mathrm{yr})$ in temperate tree species in response to post-glacial climatic 
warming [7]. While similar findings have been repeated across northern hemisphere species [23,24], the constraints of Australian fossil deposits have made detailed documentation of analogous changes along southern latitudes difficult. The use of climatic models has proved to be an informative alternative in predicting the turn-over of rainforest habitats differentially distributed along altitudinal gradients of eastern Australia [25].

The rapid climate fluctuations of the Pleistocene have had a considerable impact on intraspecific variation of many species, and left distinct genetic signatures [26,27]. Probabilistic models can help interpret such genetic signatures into ancestral demographic patterns [28]. Multi-locus analyses have proved essential for such queries [29], and accounting for historical climatic processes enables ancestral queries to be adequately addressed [26].

\subsection{Habitat Fragmentation and Loss of Intraspecific Di- versity}

The expansion of human land-use throughout the world has fragmented once continuous habitats into habitat islands. Although they are naturally fragmented, vast tracks of East Australian lowland rainforest were removed by clearing in the last 200 years, increasing the risk of localised extinctions [30]. Fragmentation and isolation increase the likelihood of population decline/bottlenecks by increasing the susceptibility of fragmented habitats to invasive species and fire [31]. Furthermore, fragmentation reduces gene flow/connectivity between populations that consequently reduces diversity and adaptive potential [32]. With regard to interspecific versus intraspecific diversity, conservation planning has focused more on the pattern (representation) than process (persistence), concentrating resources on the conservation of interspecific diversity rather than the processes responsible for intraspecific diversification and incipient speciation [33]. More recently, the amount of intraspecific variation has been considered as a key parameter to determine populations to prioritize for protection purposes [11,34].

\subsection{Our Study System}

Earlier studies on Podocarpus elatus R.Br. ex Endl. (Podocarpaceae) found agreement between genetic and Climate Envelope Model (CEM) disjunctions across the Clarence River Corridor biogeographic barrier [17]. Also, we reported modelled palaeodistribution and differential post-glacial range shift [35]. Here we infer the future distribution of genetic diversity using investigation of the signature of past demographic processes with a probabilistic model based on molecular data. Changes in future CEM distributions allowed demographic trends and trajectories to be developed. distributions allowed ascertaining demographic trends and trajectories of populations to develop prudent conservation strategies. Here we refer regularly to, and build upon, these previous works $[17,35]$ to understand the deeper evolutionary history and to compose appropriate conservation strategies for the species. We have sub-sampled the genetic data from these previous works [17,35] and generated an additional HapSTR marker for a coalescent-based analysis to infer demographic history and splitting time, and have pro- jected the current climatic envelope [17] onto an ensemble of future climate scenarios [25].

We hypothesise that genetic/demographic change and range expansion/contraction trends in P. elatus associated with the Clarence River Corridor are indicative of the future distribution and degree of adaptive potential in this longlived species, and that future conservation strategies may be more successful if distributional and demographic inference, based upon reliable observational data, is made. In particular, we aim to answer the following questions:

1. What are the coalescent-based estimates of ancestral demographic patterns and divergence times in Podocarpus elatus and how do these relate to climate change?

2. What is the predicted distribution of Podocarpus elatus for the IPCC $4^{\text {th }}$ Assessment Report climatic estimates of 2050 ?

3. Based on these findings, what are the appropriate conservation and management strategies for Podocarpus elatus?

\section{MATERIALS AND METHODOLOGY}

\subsection{Study Species}

Podocarpus elatus is a late successional, mature-phase conifer, with a wide latitudinal distribution $\left(2500 \mathrm{~km}, 20^{\circ}\right.$ of latitude) in East Australian rainforest. The species prefers drier rainforest and ecotonal rainforest communities [36]. It is commonly found with Araucaria spp. both currently and in the fossil record [37-40]. The palynological record suggests that in the Australian Wet Tropics, gymnosperms expanded during glacial maxima [20], and it is likely that the cool, dry conditions of the last glacial maximum (LGM; 21 ka) also favoured $P$. elatus. However, while southern fossil records support a decline in abundance for $P$. elatus since the LGM $[37,40,41]$, in the north the co-occurrence of a number of Podocarpus species and the classification of pollen to generic-level reduce the interpretative power of the limited deposits available.

In previous studies, sampling was designed to include the full distribution range of the species, i.e. 334 individuals from 32 populations; [35]. In this study, twenty-eight mature individuals from three populations (Fig. 1 and Table 1) were selected to investigate splitting time and effective population size in relation to two genetic regions separated by the Clarence River Corridor [17] so as to reveal the ancestral demographic processes responsible for the current genetic diversity/structure in the P. elatus.

The populations were selected based on their location and genetic connectivity in relation to the Clarence River Corridor (CRC) and are: 1) Porrots Brush (seven individuals) at the southern distributional range limit of the species, i.e. preserved trees on cleared land. 2) Bundagen (11 individuals) at the southern side of the CRC biogeographic barrier in the central range of the species. 3) Mount Glorious (10 individuals) at the northern side of the CRC biogeographic barrier in the central range of the species. By using only mature individuals (i.e. $>100$ years old) in the coalescent-based analysis, we increase the likelihood of accurately predicting natural demographic processes unaffected by anthropogenic 
Table 1. Details for the Three P. elatus Populations Used in the Study, Including the Number of Mature Individuals Sampled for the Coalescent-based Analysis (N) and Location (Decimal Latitude and Longitude). The Clarence River Corridor Occurs between Populations Two and Three. Allelic Richness $\left(R_{S}\right)$, Weir and Cockeram's Inbreeding Co-efficient (f) with Significance Level (None were Significant) were Estimated from Four Microsatellite Loci. Unbiased Diversity (uh) with Standard Error was Estimated from Five Sequence Loci

\begin{tabular}{|c|c|c|c|c|c|c|c|}
\hline & POPULATION & N & LAT & LONG & Rs $_{\mathbf{S}}$ & f & uh \\
\hline \hline 1 & Porrots Brush (SNSW) & 7 & -34.6548 & 150.813 & 5.09 & 0.061 & $0.371 \pm 0.176$ \\
\hline 2 & Bundagen (NNSW) & 11 & -30.4315 & 153.075 & 6.00 & 0.108 & $0.419 \pm 0.141$ \\
\hline 3 & Mt Glorious (SQLD) & 10 & -27.3230 & 152.757 & 5.25 & 0.094 & $0.496 \pm 0.101$ \\
\hline
\end{tabular}

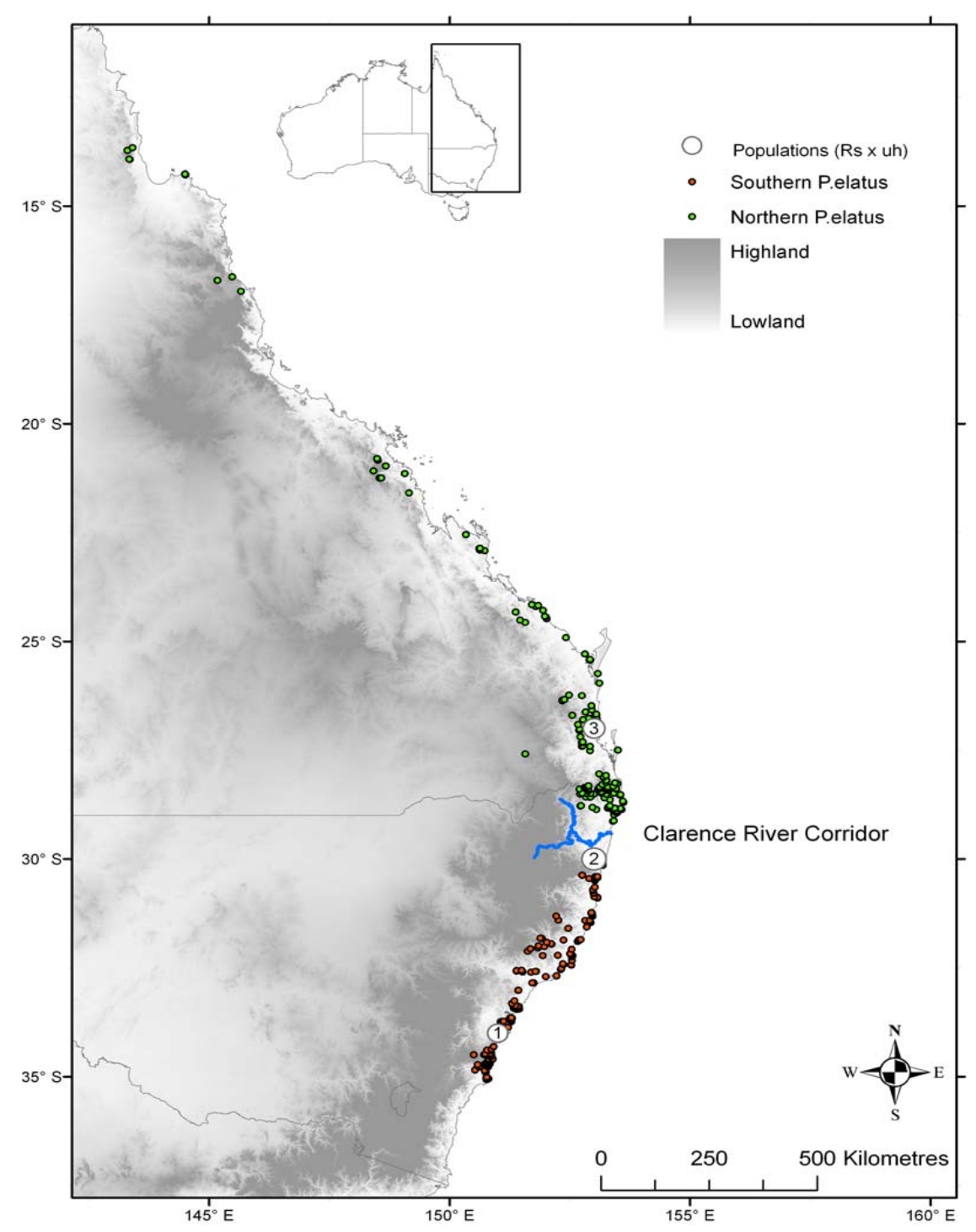

Fig. (1). The distribution of Podocarpus elatus showing genetically differentiated population groups; southern group is red and northern is green [17]. The Clarence River Corridor dividing the groups is shown. The three populations used for the coalescent-based analysis are shown and the sizes of their representative circles are relative to allelic richness (Rs) x unbiased heterozygosity (uh).

disturbance. The populations represent areas of interest with regard to observed genetic and distributional disjunctions (Fig. 1).

\subsection{Occurrence Data and Species Distribution Modelling}

Environmental data was used for spatial modelling of the individual genetic clusters (Fig. 1) to infer the future distri- 
Table 2. Details of the 13 Atmospheric Oceanic Global Circulation Models (AOGCMs) Used for Projecting MaxEnt Models Onto Future Climate Conditions

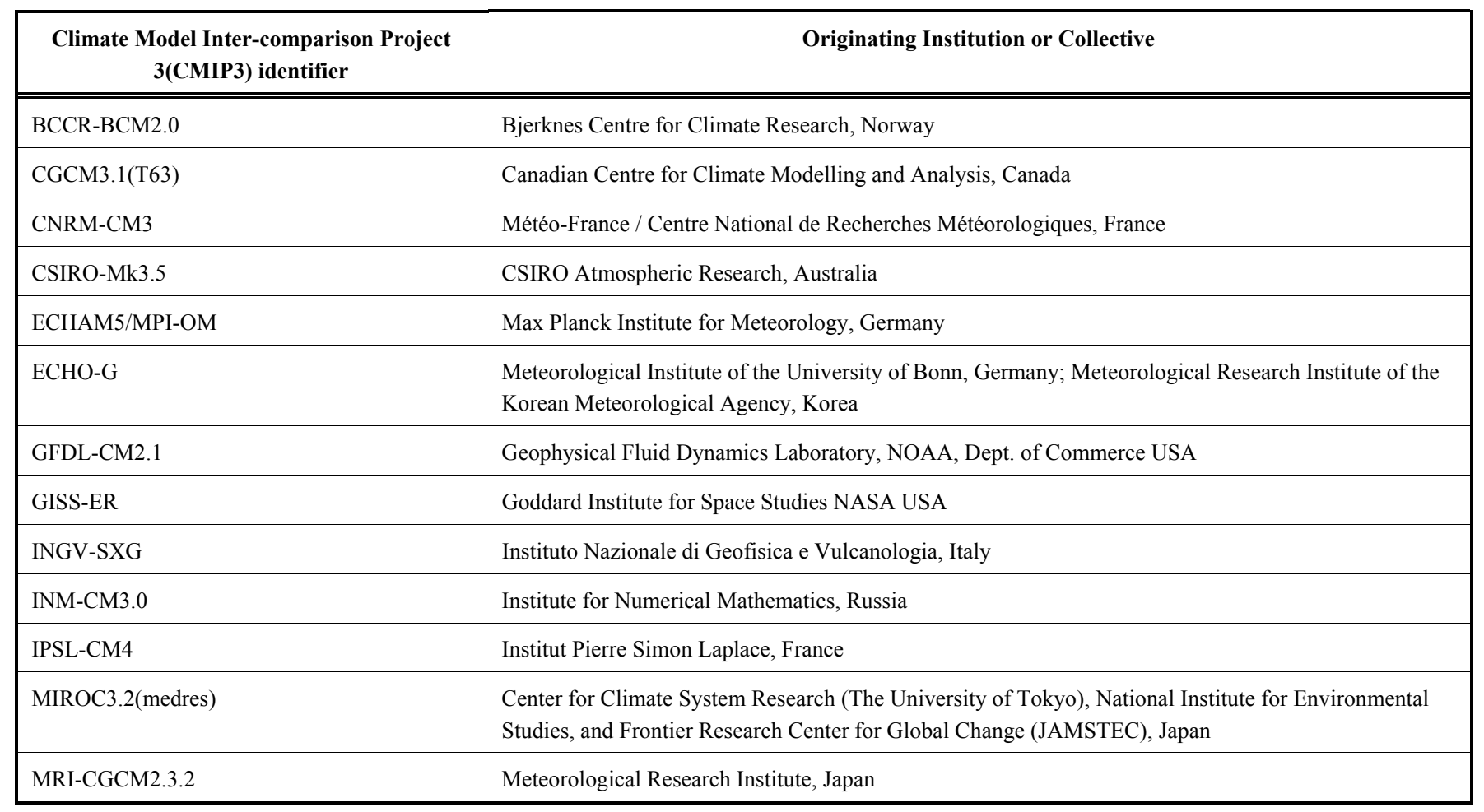

bution of genetic diversity (Fig 2). This included 11 variables from the WORLDCLIM 1.4 database [42] and 405 occurrence records (224 southern and 181 northern records) compiled and verified from all Australian Herbaria and the Office of Environment and Heritage's vegetation survey database (http://www.environment.nsw.gov.au/research/ VISplot.htm), and Atlas of NSW Wildlife (http://wildlifeatlas.nationalparks.nsw.gov.au/wildlifeatlas/watlas.jsp) databases. We refined the current model using methodology described by Mellick et al. [17]. The 11 environmental variables were: annual mean temperature, minimum temperature of the coldest month, mean temperature of the wettest quarter, mean temperature of the driest quarter, annual precipitation, precipitation of the driest month, precipitation seasonality (coefficient of variation), precipitation of the wettest quarter, precipitation of the driest quarter, precipitation of the warmest quarter and precipitation of the coldest quarter.

The Climate Envelope Models (CEMs) were developed using observed $20^{\text {th }}$ Century climate data and were projected onto the estimated climate for the decade centred on 2050. Model training and projection were performed using MAXENT 3.3.3e [43] (software available from http://www.cs.princeton.edu/ schapire/maxent, last accessed 4 January 2012). To account for uncertainties in the future climate data, we derived data from 13 coupled atmospheric oceanic global circulation models (AOGCMs; Table 2) used in fourth assessment report of the Inter-governmental Panel on Climate Change (IPCC) [3], which provided the raw temperature and precipitation variables needed to compute the derived bioclimatic variables used to fit the CEMs. We chose AOGCM model runs for the A2 greenhouse gas scenario [44] because assessments of observed trends in green house gas levels suggest that this scenario closely matches the observed trends [45]. Raw AOGCM data was obtained from the Climate Model Inter-comparison Project dataset (https://esg.llnl.gov:8443/home/publicHomePage.do, last accessed 4 January 2012). Using a custom-written program, we downscaled the coarsely-gridded AOGCM data using bicubic spline interpolation [46] to the same 30 arc second grid as the WorldClim data [42] used to fit the original MAXENT models. We then computed the bioclim variables for each AOGCM also using a custom-written program. Using the projection function of MAXENT, a projection was made onto each AOGCM and then averaged to produce an ensemble consensus map of predicted climate suitability in the decade centred on 2050.

This correlative approach provides a robust method, based upon climate envelope models and a novel AOGCM ensemble, to predict the future distribution of species [25]. Climatic models for Podocarpus elatus inferred that the current geographic separation of the northern and southern envelopes corresponds to the genetically differentiated population groups [17]. Model performance and assessment are outlined by Mellick et al. [35].

\subsection{DNA Microsatellite and Sequence Analysis}

Ten markers from nuclear and paternally inherited chloroplast genomes [47], including three types of markers: 1) sequence [35], 2) microsatellite [17] and 3) HapSTR markers were used in the coalescent-based analysis. 
The four microsatellite loci (PeA16BGT, PeB31BGT, PeC19BGT, PeD14BGT) used in this study were isolated and primers developed from the methodology set out by Almany et al. [47]. FSTAT 2.9.3 [48] was used to calculate allelic richness $\left(R_{S}\right)$ and the inbreeding coefficient $(f)$ for each population from the four microsatellite loci (Table 1). Methodology regarding PCR conditions, optimisation procedures and cross-transferability results are outlined by Almany et al. [47]. Microsatellite assessment is outlined by Mellick et al. [17]. Sequencing methodology is outlined by Rossetto et al. [49].

The five sequenced loci used in this study represented microsatellite flanking regions from PeA16BGT, PeA45BGT, chloroplast locus PeB37BGT, PeC26BGT and PeD13BGT $[35,47]$. GENEIOUS 4.8 .5 was used to edit and align nuclear DNA sequence data (which included ambiguous codes for heterozygous bases). DNAsp v5 imported these unphased formats and phased the diploid sequence data into haplotype sequence data, and each individual was represented by two haplotype sequences (i.e. homozygous individuals had two identical sequences) for each sequenced nuclear loci. GenAlEx 6.4.1 [50] was used to estimate unbiased genetic diversity with standard error (uh) for each population from the five sequenced loci (Table 1).

An Hap STR locus (PeA16 BGT allele length and PeA16 BGT flanking sequence) unique to this study was generated by combining the allele length genotypes and sequence haplotypes for each individual in the study. The variation in microsatellite length and sequence (between priming site and the repeat motif) is combined to reveal further information [51]. Phase determination between microsatellite genotype and sequenced haplotype can be problematic [52]. Subjective determination of phase was possible due to the majority of both sequence and allele size being of one class (i.e. more than $75 \%$ of genotypes/haplotypes were of one size/type class: Mellick et al. [17,35]. So, based on the comparable proportion of allele size classes to sequence haplotypes, the phase of each individual in this study was able to be determined.

\subsection{Coalescence-based Analyses}

The data set was analysed with the multi-population isolation-with-migration model implemented in the program IMa2 [28]. Posterior probabilities for six parameters were calculated within $95 \%$ highest posterior density intervals in each of three pair wise comparisons. These were pair-wise migrations $(m 1->m 2, m 2->m 1)$, the time since divergence $(t)$ and effective population sizes (population 0 , population 1 and ancestral population 2) between three adjacent populations either side of the CRC (Table 1 and Fig. 1). A threepopulation model was run based on the tree string developed from the three pairwise comparisons. Microsatellite marker mutation rates [53], sequenced markers mutation rates [54,55], and HapSTR mutation rate [51] were tested and approximated from relevant literature.

One hundred year generation time was estimated according to age cohort representation within the three populations under study and regression; determined from cultivated trees of known age (The Royal Botanic Gardens and Domain Trust, Sydney: 1.74 (growth factor) $\mathrm{x}$ diameter at breast height $(\mathrm{cm})=$ approximate age in years). Although these trees have been cultivated and looked after, their slow mature growth rate and old age warrant the comparison to the similar sized 28 mature individuals naturally sourced for the coalescent-based analysis. The coalescent-based analysis was applied as follows: multiple preliminary runs were conducted to assess convergence and adjust prior ranges ( $\mathrm{M}$ mode). Markov Chain Monte Carlo (MCMC) runs were carried out with a burn-in of 10000000 steps with 100000 genealogies sampled per locus (for a total of 10000000 iterations). Inheritance scalars were set as 1 for nuclear markers, and 0.25 for the plastid marker. A prior file was used to set the final prior parameters based on the upper bound limits of the likelihood distribution for each parameter.

Exponential prior distribution for migration parameters was used due to the previous evidence of divergence [17] and that divergence is not expected unless gene flow is low $[28,56]$. To ensure appropriate mixing, runs were replicated three-times to confirm model convergence, i.e. trend-line plots showed no observable trends, as suggested in the program documentation. The methodology is included in IMa2 documentation (http://genfaculty.rutgers.edu/hey/software). Nucleotide substitution for each of the sequenced loci was determined via MODELTEST 3.7 [57]. The stepwise mutation model [58] was assumed for all microsatellite loci, the HKY mutation model [59] was applied for the sequenced loci and the infinite sites mutational model was applied to the HapSTR locus $[51,60]$.

This method infers ancestral demographic patterns and climate driven trends for this long-lived rainforest species. The post-glacial demographic trajectory is later interpreted with future climate envelope models and the observed fossil record to determine the likely future distribution of genetic diversity.

\section{RESULTS}

\subsection{Past-current-future Habitat Suitability}

The Climate Envelope Models (Fig. 2) predict that the climatic envelope of $P$. elatus populations south of the CRC will continue to contract coastward (A2 2050 scenario) as it has since the last glacial maximum (LGM, $21 \mathrm{ka}$ ) [35], and will shift south beyond the present distributional limit along the highlands of NSW and Victoria. The climatic envelope supporting northern populations is predicted to expand by 2050, following a contraction since the Holocene Climatic Optimum (HCO, $6 \mathrm{ka})$ and a significant expansion since the LGM.

The northern CEM infers expansion beyond the northern distributional limit and south beyond the CRC this century. The distance between the two-modelled ranges is at its broadest at the LGM [35]. Thus, the disparity with respect to climate driven population expansion and contraction processes between the northern and the southern genetic clusters [35] is shown to continue in the future.

\subsection{Population Demographics and Divergence}

A decline in effective population size is inferred during the ancestral split at 105 thousand years ago (ka), where posterior probability peaked (Table 3: $\theta 3-4$ and $\mathrm{t} 1$ ) at the maxi- 


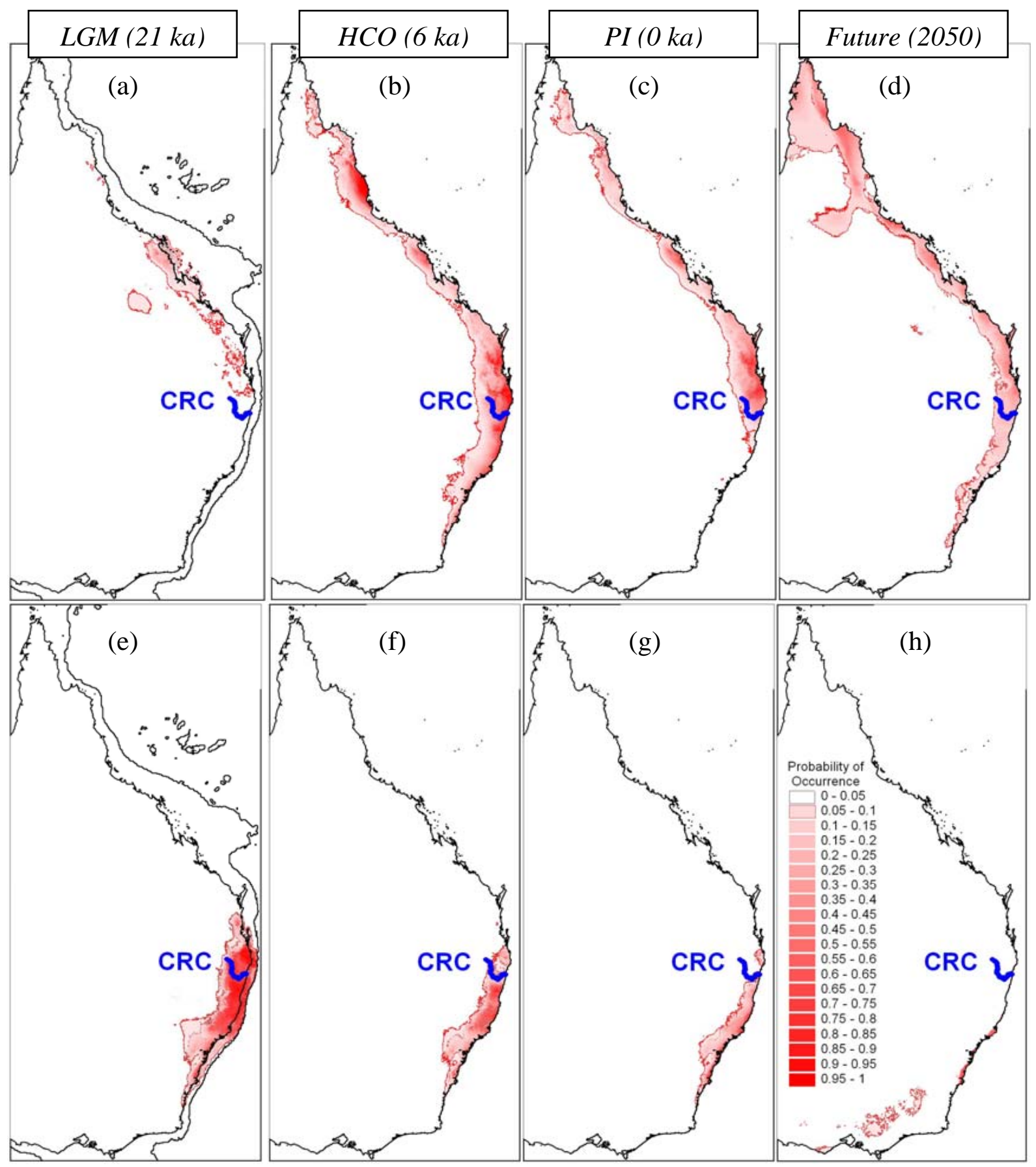

Fig. (2). Climate Envelope Models for Podocarpus elatus north (a, b, $\mathbf{c}$ and $\mathbf{d})$ and south $(\mathbf{e}, \mathbf{f}, \mathbf{g}$ and $\mathbf{h})$ of the Clarence River Corridor biogeographic barrier in eastern Australia for 21 ka Last Glacial Maximum (a and e), lowered bathymetry s6 ka Holocene Climatic Optimum (b and f), 0 ka Pre-industrial (c and g), and A2 2050 future time periods (d and h). Red borders around projected distributions do not reflect probability of occurrence.

mum likelihood estimate (MLE) within the $95 \%$ confidence highest posterior density interval (HPD95 low - HPD95 high). The migration parameters in the model did not converge and were not informative. A later split between southern populations one and two (Table 3: $\theta 1-2$ and $t 2$ ) is shown to have occurred close to the LGM at 19 ka during which time another decline in effective population size was shown.

\section{DISCUSSION}

\subsection{Declining Abundance and Changes in Habitat Suit- ability}

Climate Envelope and molecular models (Fig. 2 and Table 3) were in agreement with respect to ancestral climate driven divergence either side of the Clarence River Corridor 
Table 3. The Inferred Genetic History of Three Podocarpus elatus Populations Representing the Southern [1. Southern New South Wales (Sth NSW) and 2. Northern New South Wales (Nth NSW)] and Northern [3. Southern Queensland (Sth QLD)] Ranges Either side of the Clarence River Corridor (CRC) Biogeographic Barrier. The 95\% Highest Posterior Density Intervals (HPD95 low - HPD95 high) are Tabulated for Effective Population Sizes (01- 05) and Splitting Times (t1; First Split Either Side of the CRC between Sth QLD and NSW Ancestral Populations: t2; Second Split between Sth and Nth NSW). The Maximum Likelihood Estimate (MLE) is the Curve Height (i.e. mode) of Marginal Posterior Probability for Each Parameter. The Difference between the Original Parameter Values (i.e. Curve Height of Marginal Posterior Probability) and the Rescaled Population Size and Time Parameter Values, is that the Latter Use Marginal Distribution Values in Demographic Units. None of the Migration Parameters Converged and were Left Out of the Table Accordingly

\begin{tabular}{|c|c|c|c|c|c|c|c|}
\hline DATA SET & Sth NSW $\theta 1$ & Nth NSW $\theta 2$ & Sth QLD $\theta 3$ & NSW ancestral $\theta 4$ & All ancestral $\theta 5$ & t1 & t2 \\
\hline MLE & 0.1825 & 0.1673 & 0.5655 & 0.888 & 34.04 & 0.0475 & 0.0095 \\
\hline HPD95 High & 2.918 & 0.7748 & 1.556 & 12.11 & 54.44 & 0.1475 & 0.0435 \\
\hline \multicolumn{8}{|c|}{ rescaled population size ( $\theta$ : individuals) and time (t:1000 years) parameter units } \\
\hline HPD95 Low & 37.55 & 71.34 & 953.7 & 0 & 109132 & 35.042 & 3.004 \\
\hline HPD95 High & 14605 & 3878 & 7787 & 60636 & 272530 & 295.357 & 87.105 \\
\hline
\end{tabular}

(CRC) in Podocarpus elatus. The coalescent-based analysis shows a series of demographic events that aligned with climatic fluctuations, which may explain the current differentiation in relation to the CRC, but importantly they show a decline in abundance of $P$. elatus that pre-dates the last glacial maximum (LGM; $21 \mathrm{ka})$. The southern climatic envelope model shows a contraction in response to post-glacial warming (21 - $0 \mathrm{ka})$ and this is in agreement with the observed fossil record [37,39-41]. Interestingly in the fossil record a longer-term decline since the last interglacial (130 $0 \mathrm{ka}$ ) has been observed among other podocarps $[20,61,62]$, including P. elatus [39-41]. Bottleneck events are likely to have contributed to the divergence patterns (i.e. genetic disjunctions) between population groups of $P$. elatus and the low diversity/abundance of other rainforest conifers in Australia $[20,62-64]$.

The coalescent analysis suggests that the divergence between either side of the CRC occurred prior to the LGM and was accompanied by a decline in effective population size (105 ka; Table 3). The distinction/divergence between these genetic regions is likely to have been maintained since by climatic/latitudinal gradients (e.g. precipitation seasonality) and subsequent selective filtering associated with the CRC (e.g. phenological variation).

The 2050 predictions show that the climatic conditions supporting the southern populations will contract coastward into microhabitat pockets and extend south mainly along the southern highlands (Fig. 2). The climatic conditions supporting the northern populations will expand south approximately $600 \mathrm{~km}$ (i.e. $15 \mathrm{~km} / \mathrm{yr}$ ) and north along the coast. These estimates show that the climatic envelopes for both genetic regions are shifting south in agreement with the general poleward movement of species in response to global warming [65].

\subsection{Macleay Overlap Zone: an Important Area of Ad- mixture}

The Macleay Overlap Zone (MOZ) [66] is the centre of $P$. elatus genetic diversity and is a critical area of habitat overlap (Fig. 2), between the expanding low-diverse northern region and the contracting high-diverse southern region [35], where the species is likely to maintain diversity and survive across climatic cycles. Periods of isolation followed by migration decrease inbreeding and relive the genetic load of populations thus increasing the likelihood of survival. The MOZ is an important crossroad to floristic exchange between the tropical, subtropical and temperate rainforests [67-69], as observed in P. elatus haplotype distribution patterns [35] that show the MOZ as an area of admixture between northern and southern population groups. Ongoing and future patterns of habitat loss could threaten the evolutionary potential of species [70]. In the past, climatic fluctuations have driven speciation and introgression events among latitudinally dispersed refugia, and it is safe to assume that current anthropogenic-induced climate change may interfere with these natural evolutionary processes.

\section{CONCLUSION}

\subsection{Is Podocarpus elatus More Threatened than its Cur- rent Range Suggests?}

Past-current-future modelling (Fig. 2) suggests that the two population groups respond differently to climate change, and that both are subjected to expansion/contractions cycles indicative of community turn-over [20,25]. This emphasizes the sensitivity of this species to climatic fluctuation and, when considering its fragmented distribution along a broad latitudinal range, the likelihood that this species may survive climatic cycles within dispersed refugia and microhabitats, 
e.g. ecotones, ridgelines, rainforest remnants [19]. Although the species has long generation periods of up to 600 years, successful recruitment and establishment are reliant on abiotic (e.g. fire frequency and climate) as well as biotic factors (e.g. competition and light availability). Current spatial displacement to boundary communities $[17,36]$ away from the increased competition of core communities [71] may have facilitated the survival of populations in the past, yet may now expose $P$. elatus to anthropogenic disturbance, such as more frequent burning, non-indigenous invasive species and possible localised extinction.

The nature of these ecotonal communities (e.g. nutrient poor areas, fire prone, less competition) affords Podocarpus an advantage (i.e. less vigorous competition [19,71]). The micro-environmental character and the sheltered ecology of ecotonal micro-habitats may have facilitated survival in areas of low climatic suitability. These fragmented habitats, considering the dioecious nature of the tree (i.e. out-crosser), are especially vulnerable to the effects of isolation, genetic drift and inbreeding, as shown in other Australian rainforest conifers $[63,64]$.

Our combined analyses have shown that despite its current wide range and it common status, Podocarpus elatus is in long-term decline (Table $\mathbf{3}$, i.e. decreasing effective population size), and its survival across its distributional range may be linked to the availability of microhabitats including ecotones. Rainforest boundary communities are particularly susceptible to anthropogenic disturbance and, where situated close to the coast (i.e. littoral/gallery rainforest), this habitat is under further threat from the sea-level rise (i.e. storm surges) anticipated this century [72].

\subsection{Conservation Strategies for Podocarpus elatus - a Key Component of Threatened Rainforest Communities}

Range shift is part of the natural adaptive process [33], but during previous climate fluctuations, range shift has been unhindered by human land-use. In order to conserve the natural genetic constitution and adaptive potential of species in general, protected avenues/assisted migration for predicted range shift will need to be integrated into the human land-use matrix. Predictive distributional modelling and the understanding of gene flow dynamics provide a method to interpret current distribution patterns and potentially anticipate, and accommodate, rapid migration rates as a result of projected anthropogenic-induced climate change.

Our data suggest that conservation and management should be focused around the southern populations and Macleay Overlap Zone; where most of the species' diversity resides and where sustained habitat suitability in response to post-glacial warming and future scenarios occurs. The southern populations (Fig $\mathbf{2 h}$ ) are under threat of localised extinction, and therefore should be a target of conservation strategies. Locally adapted genetic variants may be harboured by these populations. Conservation strategies may involve the extension of habitat corridors to accommodate future rangeshift and potentially assisted migration of genetically rich stock under threat of localised extinction into areas of high habitat suitability (i.e. the Macleay Overlap Zone).

\section{CONFLICT OF INTEREST}

The authors confirm that this article content has no conflicts of interest.

\section{ACKNOWLEDGEMENTS}

This research was funded by the Australian Research Council Discovery Grant (DP0665859). The authors thank The Royal Botanic Gardens and Domain Trust, Sydney, and the University of Adelaide. The authors particularly thank Andrew Ford (CSIRO), Rebecca Johnson, Bob Coveny, Phillip Greenwood, NSW National Parks and Wildlife, and Robert Kooyman for their assistance in undertaking collections and field observations, and Simon Ho (The University of Sydney) and Paul Rymer (The University of Western Sydney) for their support with regard to multi-locus coalescence-based analysis.

\section{REFERENCES}

[1] Lenton TM, Held H, Kriegler E, et al. Tipping elements in the Earth's climate system. Proc Natl Acad Sci USA 2008; 105: 178693.

[2] Novacek MJ, Cleland EE. The current biodiversity extinction event: scenarios for mitigation and recovery. Proc Natl Acad Sci USA 2001; 98: 5466-70.

[3] Solomon S, Qin D, Manning M, et al. Climate Change 2007: The Physical Science Basis. Cambridge: Cambridge University Press 2007.

[4] Parmesan C. Ecological and Evolutionary Responses to Recent Climate Change. Annu Rev Ecol Evol Syst 2006; 7: 637-9.

[5] Beaumont LJ, Hughes L. Potential changes in the distributions of latitudinally restricted Australian butterfly species in response to climate change. Glob Change Biol 2002; 10: 954-71.

[6] Pye MG, Gadek PA. Genetic diversity, differentiation and conservation in Araucaria bidwillii (Araucariaceae), Australia's Bunya pine. Conserv Genet 2004; 5: 619-29.

[7] McLachlan JS, Clark JS, Manos PS. Molecular indicators of tree migration capacity under rapid climate change. Ecology 2005; 86: 2088-98.

[8] Pennington RT, Lavin M, Prado DE, Pendry CA, Pell SK, Butterworth CA. Historical climate change and speciation: neotropical seasonally dry forest plants show patterns of both Tertiary and Quaternary diversification. Philos Trans R Soc Lond B Biol Sci2004; 359: 515-37.

[9] Williams SE, Bolitho EE, Fox S. Climate change in Australian tropical rainforests: an impending environmental catastrophe. Philos Trans R Soc Lond B Biol Sci 2003; 270: 1887-92.

[10] Aitken SN, Yeaman S, Holliday JA, Wang T, Curtis-McLane S. Adaptation, migration or extirpation: climate change outcomes for tree populations. Evol Appl 2008; 1: 95-111.

[11] Bonin A, Nicole F, Pompanon FO, Miaud C, Taberlet P. Population adaptive index: a new method to help measure intraspecific genetic diversity and prioritize populations for conservation. Conserv Biol 2007; 21: 697-708.

[12] Lindner M, Garcia-Gonzalo J, Kolström M, et al. Impacts of climate change on European forests and options for adaptation. Europe: Report to the European Commission Directorate-General for Agriculture and Rural Development 2008.

[13] Parmesan C, Yohe G. A globally coherent fingerprint of climate change impacts across natural systems. Nature 2003; 421: 37-42.

[14] Thuiller W, Albert C, Araujo MB, et al. Predicting global change impacts on plant species' distributions: Future challenges. Perspect Plant Ecol Syst 2008; 9: 137-52.

[15] Bresson CC, Vitasse Y, Kremer A, Delzon S. To what extent is altitudinal variation of functional traits driven by genetic adaptation in European oak and beech? Tree Physiol 2011; 31: 1164-74. 
[16] Brodribb T, Hill RS. The importance of xylem constraints in the distribution of conifer species. New Phytol 1999; 143: 365-72.

[17] Mellick R, Lowe A, Rossetto M. Consequences of long- and shortterm fragmentation on the genetic diversity and differentiation of a late successional rainforest conifer. Aust J Bot 2011; 59: 351-62.

[18] Waltari E, Hijmans RJ, Peterson AT, Nyari ÃrdS, Perkins SL, Guralnick RP. Locating Pleistocene refugia: comparing phylogeographic and ecological niche model predictions. PLoS ONE 2007; 2: e563.

[19] Brodribb TJ, Hill RS. The rise and fall of the Podocarpaceae in Australia: a physiological explanation. In: Hemsley A, Poole I, Eds. Evolution of plant physiology. London: Academic Press 2003; pp. 381-99.

[20] Kershaw AP, Bretherton SC, van der Kaars S. A complete pollen record of the last $230 \mathrm{ka}$ from Lynch's Crater, north-eastern Australia. Palaeogeogr Palaeoclimatol Palaeoecol 2007; 251: 23-45.

[21] Lee TM, Jetz W. Unravelling the structure of species extinction risk for predictive conservation science. Philos Trans R Soc Lond B Biol Sci 2011; 278: 1329-38.

[22] Thomas CD, Cameron A, Green RE, et al. Extinction risk from climate change. Nature 2004; 427: 145-8.

[23] Brewer S, Cheddadi R, de Beaulieu JL, Reille M. The spread of deciduous Quercus throughout Europe since the last glacial period. For Ecol Manag 2002; 156: 27-48.

[24] Petit RJ, Brewer S, Bordacs S, et al. Identification of refugia and post-glacial colonisation routes of European white oaks based on chloroplast DNA and fossil pollen evidence. For Ecol Manag 2002; 156: 49-74.

[25] Mellick R, Wilson PD, Rossetto M. Post-glacial spatial dynamics in a rainforest biodiversity hot spot. Diversity 2013; 5: 124-38.

[26] Carstens BC, Knowles LL. Shifting distributions and speciation: species divergence during rapid climate change. Mol Ecol 2007; 16: 619-27.

[27] Hewitt G. The genetic legacy of the Quaternary ice ages. Nature 2000; 405: 907-13.

[28] Hey J. Isolation with migration models for more than two populations. Mol Biol Evol 2010; 27: 905-20.

[29] Hey J, Nielsen R. Multilocus methods for estimating population sizes, migration rates and divergence time, with applications to the divergence of Drosophila pseudoobscura and D. persimilis. Genetics 2004; 167: 747-60.

[30] Bowman D. Australian rainforests: islands of green in the land of fire. Cambridge: Cambridge University Press 2000.

[31] Ewers RM, Didham RK. Confounding factors in the detection of species responses to habitat fragmentation. Biol Rev 2006; 81: 11742.

[32] Young A, Boyle T, Brown T. The population genetic consequences of habitat fragmentation for plants. Trends Ecol Evol 1996; 11: 413-8.

[33] Moritz C. Strategies to protect biological diversity and the evolutionary processes that sustain it. Syst Biol 2002; 51: 238-54.

[34] Harrington MG, Gadek PA. A species well travelled - the Dodonaea viscosa (Sapindaceae) complex based on phylogenetic analyses of nuclear ribosomal ITS and ETSf sequences. J Biogeogr 2009; 36: 2313-23.

[35] Mellick R, Lowe A, Allen C, Hill RS, Rossetto M. Palaeodistribution modelling and genetic evidence highlight differential postglacial range shifts of a rain forest conifer distributed across a latitudinal gradient. J Biogeogr 2012; 39: 2292-302.

[36] Harden G, McDonald B, Williams J. Rainforest trees and shrubs: a field guide to their identification. Nambucca Heads: Gwen Harden Publishing 2006.

[37] Black MP, Mooney SD, Martin HA. A >43,000-year vegetation and fire history from Lake Baraba, New South Wales, Australia. Quat Sci Rev 2006; 25: 3003-16.

[38] Longmore ME. Quaternary palynological records from perched lake sediments, Fraser Island, Queensland, Australia: Rainforest, forest history and climatic control. Aust J Bot 1997; 45: 507-26.

[39] Shimeld P. A vegetation history of Moffats Swamp, Port Stephens, NSW. Thesis. Newcastle: University of Newcastle 1995.

[40] Shimeld P. The Last Interglacial at Port Stephens, New South Wales. In: Haberle S, Stevenson J, Eds. Australasian Quaternary
Association Biennial Conference; 2004; Cradle Mountain Tasmania: AQUA 2004 Program and Abstracts; 2004.

[41] Williams NJ, Harle KJ, Gale SJ, Heijnis H. The vegetation history of the last glacial-interglacial cycle in eastern New South Wales, Australia. J Quat Sci 2006; 2: 735-50.

[42] Hijmans RJ, Cameron SE, Parra JL, Jones PG, Jarvis A. Very high resolution interpolated climate surfaces for global land areas. Int $\mathrm{J}$ Climatol 2005; 25: 1965-78.

[43] Phillips SJ, Anderson RP, Schapire RE. Maximum entropy modeling of species geographic distributions. Ecol Modell 2006; 190: 231-59.

[44] Nakicenovic N, Alcamo J, Davis G, et al. Special Report on Emissions Scenarios : a special report of Working Group III of the Intergovernmental Panel on Climate Change. Cambridge: Cambridge University Press 2000.

[45] Raupach MR, Marland G, Ciais P, et al. Global and regional drivers of accelerating CO2 emissions. Proc Natl Acad Sci USA 2007; 104: 10288-93.

[46] Press WH, Teukolsky SA, Vetterling WT, Flannery BP. Numerical Recipes in $\mathrm{C}++$. The art of scientific computing. $2^{\text {nd }}$ ed. Cambridge, U.K.: Cambridge University Press 2002.

[47] Almany GR, De Arruda MP, Arthofer W, et al. Permanent Genetic Resources added to Molecular Ecology Resources Database 1 May 2009-31 July 2009. Mol Ecol Res 2009; 9: 1460-6.

[48] Goudet J. FSTAT (Version 1.2): a computer program to calculate F-statistics. J Hered 1995; 86: 485-6.

[49] Rossetto M, Crayn D, Ford A, Mellick R, Sommerville K. The influence of environment and life-history traits on the distribution of genes and individuals: a comparative study of 11 rainforest trees. Mol Ecol 2009; 18: 1422-38.

[50] Peakall R, Smouse PE. Genalex 6: genetic analysis in Excel. Population genetic software for teaching and research. Mol Ecol Notes 2006; 6, 288-95.

[51] Hey J, Won YJ, Sivasundar A, Nielsen R, Markert JA. Using nuclear haplotypes with microsatellites to study gene flow between recently separated Cichlid species. Mol Ecol 2004; 13: 909-19.

[52] Sorenson MD, DaCosta JM. Genotyping HapSTR loci: phase determination from direct sequencing of PCR products. Mol Ecol Res 2011; 1068-75.

[53] Schlotterer C. Evolutionary dynamics of microsatellite DNA. Chromosoma 2000; 109: 365-71.

[54] Biffin E, Conran J, Lowe A. Podocarp evolution: a molecular phylogenetic perspective. In: Turner BL, Cernusak LA, Eds. In Ecology of the Podocarpaceae in tropical forests: Smithsonian contributions to botany, No. 95. Washington, D.C: Smithsonian Institution Scholarly Press 2011; pp. 1-20.

[55] Biffin E, Hill RS, Lowe AJ. Did Kauri (Agathis: Araucariaceae) Really survive the Oligocene drowning of New Zealand? Syst Biol 2010; 59: 594-601.

[56] Hey J. The divergence of chimpanzee species and subspecies as revealed in multipopulation isolation-with-migration analyses. Mol Biol Evol 2010; 27: 921-33.

[57] Posada D, Crandall KA. MODELTEST: testing the model of DNA substitution. Bioinformatics 1998; 14: 817-8.

[58] Kimura M, Ohta T. Stepwise mutation model and distribution of allelic frequencies in a finite population. Proc Natl Acad Sci USA 1978; 75: 2868-72.

[59] Hasegawa M, Kishino H, Yano T. Dating of the human-ape splitting by a molecular clock of mitochondrial DNA. J Mol Evol 1985; 22: 160-74.

[60] Nielsen R, Wakeley J. Distinguishing migration from isolation: a markov chain monte carlo approach. Genetics 2001; 158: 885-96.

[61] Hill RS. The history of selected Australian taxa. In: Hill RS, Ed. History of the Australian Vegetation: Cretaceous to Recent. Cambridge: Cambridge University Press 1994; pp. 390-419.

[62] Kershaw AP, McKenzie GM, Porch N, et al. A high-resolution record of vegetation and climate through the last glacial cycle from Caledonia Fen, southeastern highlands of Australia. J Quat Sci 2007; 22: 481-500.

[63] Peakall R, Ebert D, Scott LJ, Meagher PF, Offord CA. Comparative genetic study confirms exceptionally low genetic variation in 
the ancient and endangered relictual conifer, Wollemia nobilis (Araucariaceae). Mol Ecol 2003; 12: 2331-43.

[64] Shapcott A. Population genetics of the long-lived Huon pine Lagarostrobos franklinii: An endemic Tasmanian temperate rainforest tree. Biol Conserv 1997; 80: 169-79.

[65] Hughes L. Biological consequences of global warming: is the signal already apparent? Trends Ecol Evol 2000; 15: 56-61.

[66] Burbidge NT. The phytogeography of the Australian region. Aust J Bot 1960; 8: 75-211.

[67] Muellner AN, Pannell CM, Coleman A, Chase MW. The origin and evolution of Indomalesian, Australasian and Pacific island biotas: insights from Aglaieae (Meliaceae, Sapindales). J Biogeogr 2008; 35: $1769-89$
[68] Sniderman JMK, Jordan GJ. Extent and timing of floristic exchange between Australian and Asian rain forests. J Biogeogr 2011; 38: 1445-55.

[69] Stork NE, Goosem S, Turton SM. Australian rainforests in a global context. In: Stroke NE, Turton SM, Eds. Living in a dynamic tropical forest landscape. Oxford: Balckwell 2008; pp. 4-20.

[70] Grivet D, Sork VL, Westfall RD, Davis FW. Conserving the evolutionary potential of California valley oak (Quercus lobata Nee): a multivariate genetic approach to conservation planning. Mol Ecol 2008; 17: 139-56.

[71] Lusk CH. Stand dynamics of the shade-tolerant conifers Podocarpus nubigena and Saxegothaea conspicua in Chilean temperate rain forest. J Veg Sci 1996; 7: 549-58.

[72] Rahmstorf S. A semi-empirical approach to projecting future sealevel rise. Science 2007; 315: 368-70.

Received: May 18, 2013

Revised: June 26, 2013

Accepted: June 26, 2013

(C) Mellick et al. Licensee Bentham Open.

This is an open access article licensed under the terms of the Creative Commons Attribution Non-Commercial License (http://creativecommons.org/licenses/by-nc/3.0/) which permits unrestricted, non-commercial use, distribution and reproduction in any medium, provided the work is properly cited. 